\title{
Relationship between pre-service mathematics teachers' knowledge, beliefs and instructional practices in China
}

\author{
Xinrong Yang ${ }^{1} \cdot$ Gabriele Kaiser $^{2,3} \cdot$ Johannes König ${ }^{4}$ (D) Sigrid Blömeke ${ }^{5}$
}

Accepted: 4 February 2020 / Published online: 11 February 2020

(c) The Author(s) 2020

\begin{abstract}
In this paper we examine the relationship between teachers' knowledge, beliefs and instructional practices based on a study with 495 Chinese pre-service mathematics teachers. The results indicate that Chinese pre-service mathematics teachers tend to hold mixed beliefs about the nature of mathematics, and a constructivist view about mathematics teaching and learning, and that they are inclined to report that their teaching is inquiry-oriented. Mathematical content knowledge (MCK) and mathematics pedagogical content knowledge (MPCK) were found not to correlate with the teachers' self-reported instructional practice, in contrast to pre-service mathematics teachers' beliefs, which showed a stronger association with their self-reported inquiry-oriented instructional practice. Moreover, pre-service teachers' dynamic beliefs about the nature of mathematics, and constructivist beliefs about mathematics teaching and learning, acted as mediators between pre-service mathematics teachers' MCK, MPCK and instructional practice respectively.
\end{abstract}

Keywords Mathematics content knowledge $\cdot$ Mathematics pedagogical content knowledge $\cdot$ Beliefs $\cdot$ Instructional practice

\section{Introduction}

The high mathematics achievement of Eastern, currently especially Chinese, students identified in large-scale international studies (see the most recent results of the PISA study; OECD 2019) has attracted considerable attention in

Johannes König

johannes.koenig@uni-koeln.de

Xinrong Yang

xinrong.yahoo@yahoo.com

Gabriele Kaiser

gabriele.kaiser@uni-hamburg.de

Sigrid Blömeke

sigrid.blomeke@cemo.uio.no

1 Southwest University, No. 2 Tiansheng Road, Beibei District, Chongqing 400715, China

2 Universität Hamburg, Von-Melle-Park 8, 20146 Hamburg, Germany

3 Australian Catholic University, Fitzroy, Australia

4 University of Cologne, Gronewaldstraße 2a, 50931 Cologne, Germany

5 Centre for Educational Measurement, University of Oslo, Postboks 1161, Blindern, 0318 Oslo, Norway researchers and policy makers all over the world for several years. Many researchers have proposed possible influencing factors for these high achievements, such as culture, language or mathematics curriculum, which may contribute to the high quality of East Asian, and currently especially Chinese students' mathematics learning outcomes (see Leung 2017 for details). Other researchers, however, compared mathematics instruction in China with that from Western countries (e.g., USA and Australia) under the assumption that mathematics instruction influences students' mathematics learning more directly (e.g., Schleppenbach et al. 2007; $\mathrm{Xu}$ and Clarke 2013, 2019). In these cross-national comparative studies, it was identified that Chinese mathematics teachers tend to structure lessons, respond to students' errors and interact with students differently. In other words, it seems that mathematics teachers in China teach mathematics in a quite different way.

However, simply identifying what teachers do differently in the classroom is not enough for a full understanding of teachers' mathematics instructional practice (Artzt and Armour-Thomas 1999). Teachers' thoughts behind the behavior should be investigated specifically and simultaneously, in order to understand why and how teachers do what they do in the classroom. Two factors, namely teacher knowledge and beliefs, have been widely 
accepted as being more closely and directly related to teachers' instructional practices (Ernest 1989; Philipp 2007; Schoenfeld, 1998). Empirical findings-identified in previous studies-were not always consistent (Francis et al. 2014), especially as the relationship between teachers' beliefs and instructional practice has been described as rather complex (Lloyd 1999). The same holds for the relationship between teacher knowledge and instructional practice.

Moreover, in previous studies in the field, teacher knowledge and teacher beliefs were quite often examined either in parallel or separated, that is, the theoretical foundation of these studies emphasized solely the role of one factor and totally ignored the other (Charalambous 2015). Therefore, it is still not clear how teachers' knowledge and beliefs interact to inform teachers' instructional practice (Lui and Bonner 2016). Furthermore, most of the previous studies in the field are mainly qualitative in nature, involving case studies of a single or a few mathematics teachers (e.g., Adler et al. 2005; Charalambous 2015; Wilkins 2008; Zhang and Wong 2015). This specificity constrains the understanding of the complex relationship among these three aspects from a more general viewpoint. Therefore, it is necessary to develop more sophisticated models of the relationship among these factors (Adler et al. 2005).

In addition to these concerns, most previous studies in the field took place in Western countries such as those in Europe, or in the USA. Little quantitative empirical evidence is available to date from non-Western countries, for example from China as an influential East Asian country with a quite unique mathematics education culture. However, both teacher knowledge and teacher beliefs have been clearly argued as socially and culturally shaped mental constructs (Felbrich et al. 2012; Schoenfeld 1998). Correspondingly, mathematics teaching can be described fundamentally as a cultural activity (Stigler and Hiebert 1999).

Therefore, from a social and cultural point of view, findings identified in previous studies conducted in Western contexts may not necessarily, or at least not fully, reflect the actual relationship of Chinese mathematics teacher knowledge, beliefs and instructional practices. In view of this gap in the literature, using the theoretical framework developed in the Teacher Education and Development Study in Mathematics (TEDS-M) and the involvement of a large number of pre-service mathematics teachers at secondary school level in China, the aim of the present study is to investigate the relationship between their knowledge, beliefs and practice. Findings will thus provide empirical quantitative evidence for the understanding of how teacher knowledge and teacher beliefs interact to guide instructional practice in the social and cultural context of China.

\section{Literature review and theoretical framework}

\subsection{Mathematics teachers knowledge}

Teacher knowledge has been modelled as a multi-faceted construct (Ball et al., 2008; Blömeke and Delaney 2012; Shulman 1987). Various frameworks have been proposed to classify the components of teacher knowledge based on the seminal work of Shulman $(1986,1987)$; amongst others, these frameworks include the widely cited classification by the project Mathematical Knowledge for Teaching (MKT, Ball et al. 2008). In this framework, teacher knowledge is mainly described as subject matter knowledge (SMK) and pedagogical content knowledge (PCK).

More recently, in the first international teacher education study conducted under the auspices of the IEA, the Teacher Education and Development Study in Mathematics (TEDS-M), teacher knowledge was the core component of professional competence of pre-service mathematics teachers at the end of their education. In the framework of TEDS-M, teacher knowledge was differentiated mainly according to mathematics content knowledge (MCK), mathematics pedagogical content knowledge (MPCK), and general pedagogical knowledge (GPK) (Blömeke and Kaiser 2014; Tatto et al. 2008). In the relevant research, these three components of teacher knowledge have been considered as important factors for effective mathematics instruction and students' mathematical learning (Baumert et al. 2010; König et al. 2014). In the present study, the framework developed in TEDS-M was adopted to describe and classify pre-service mathematics teacher knowledge in China.

Content knowledge is one of the core components of teacher knowledge in every framework mentioned above, which mainly refers to the knowledge of the subject matter and its organizing structure (Shulman 1986). Teachers' understanding of the subject matter includes the awareness of important structures of the subject and goes beyond factual knowledge (Petrou and Goulding 2011). Similarly, content knowledge in mathematics includes both the basic factual knowledge of various branches of mathematics such as algebra, geometry, number and data-included in the framework of TEDS-M - and the conceptual knowledge of structuring and organizing principles of mathematics as a discipline (Blömeke and Delaney 2012). Furthermore, as part of their content knowledge, teachers need to understand both "that something is so" and "why it is so" (Shulman 1986, p. 9). Although a deep understanding of mathematical content is needed in order to successfully accomplish their professional activities (Döhrmann et al. 2012), it needs to be taken into account that MCK differs 
from advanced academic mathematics knowledge offered at institutes of higher education, as well as from everyday mathematical knowledge (Kleickmann et al. 2013).

PCK refers to subject-specific knowledge for teaching, to make subject matter accessible to students (Shulman, 1986). Ever since the work of Shulman (1986, 1987), PCK has been regarded as an important topic in research on teaching and teacher education. Shulman (1986) identified two components that are central to PCK, namely, knowledge of instructional strategies and representations, and knowledge of students' (mis)conceptions, which was later extended. For example, in the field of mathematics education, Krauss et al. (2008) proposed within the COACTIV study that mathematics teachers' PCK should include knowledge of mathematical tasks, knowledge of students' existing conceptions and prior knowledge, and knowledge of mathematic-specific instructional strategies.

Similarly, in the TEDS-M project, the following two subdomains of PCK were differentiated: (a) curricular knowledge and knowledge of planning for mathematics teaching and learning; (b) knowledge of how to enact mathematics for teaching and learning (Tatto et al. 2008). The first subdomain mainly refers to knowledge at the pre-active stage, such as establishing appropriate learning goals, seeing connections within the curriculum, planning and selecting appropriate activities and methods, predicting typical student responses and misconceptions, and planning appropriate instructional methods. The second sub-domain refers to knowledge at the interactive stage, including knowledge of how to analyze and evaluate students' mathematical solutions and arguments, provide appropriate feedback, and analyze and diagnose students' questions (Döhrmann et al. 2012; Tatto et al. 2008).

\subsection{Mathematics teachers' beliefs}

Teachers' beliefs have been one of the most broadly investigated topics in the field of mathematics teacher education. However, so far, no agreed definition of beliefs has been developed (Leder 2019). One common trend is to define teacher beliefs as "psychologically held understandings, premises, or propositions about the world that are thought to be true" (Philipp 2007, p. 259). Similarly to the construct of teacher knowledge, teacher beliefs have been regarded to be a multifaceted construct (Cross, 2009; Ernest, 1989). In terms of mathematics teacher's beliefs, the critical components include beliefs about the nature of mathematics, and beliefs about mathematics teaching and learning (Ernest 1989; Speer 2005; Thompson 1992).

Teachers' beliefs about the nature of mathematics refer to teachers' "conscious or subconscious beliefs, concepts, meanings, rules, mental images, and preference concerning the discipline of mathematics" (Thompson 1992, p. 132). In the TEDS-M study, the framework proposed by Grigutsch et al. (1998) was employed to conceptualize the nature of mathematics from the following four views: formalismrelated view, scheme-related view, process-related view, and application-related view. Fundamentally, the first two views, namely, the formalism-related view and schemerelated view, mainly describe mathematics as being static, consisting of accurate results and infallible procedures, or as a procedure-driven body of facts and formulas (Blömeke and Kaiser 2014; Thompson 1992). In contrast, the latter two views, namely the process-related view and applicationrelated view, conceptualize mathematics as a dynamic and continually expanding domain of knowledge based on sensemaking and pattern-seeking (Felbrich et al. 2012; Thompson 1992).

Teachers' beliefs about mathematics teaching and learning refer to teachers' views on their preferred ways of teaching mathematics, and views on how it is learned, for example, their conceptions of ideal classroom teaching activities, what behaviors and mental activities are involved in mathematics learning, and what constitutes appropriate and prototypical mathematics learning activities (Chan and Elliott 2004; Ernest 1989; Thompson 1992). In the TEDSM framework, teachers' beliefs about mathematics teaching and learning were mainly differentiated between two views on mathematics teaching and learning: (1) a knowledge transmission (or "traditional") view, in which mathematics teaching is seen as a process of knowledge transmission and students receive knowledge from teachers passively, and (2) a constructivist view, in which mathematics teaching is seen as facilitating students' knowledge construction (Blömeke and Kaiser 2014; Tatto et al. 2008).

\subsection{Instructional practice}

Instructional practice refers to what happens in a teacher's classroom (Depaepe and König 2018). In literature, various ways have been used by researchers to classify instructional practice, such as teacher-centered (or traditional instruction) and student-centered (or constructivist instruction) (Hogan et al. 2013). In mathematics education, after the implementation of mathematics curriculum reform globally at around the year 2000, student-centered instruction or inquiry-based instruction has been widely advocated in many countries (Cai and Howson 2013). In such an approach to mathematics instruction, students are supposed to engage actively in meaningful and real life related mathematical problems or activities so that they can make conjectures and investigations, collect and analyze data, and communicate and collaborate with their peers. In this approach, the teacher works mainly as a facilitator guiding students' activities (Wilkins 2008). 
Mathematics instruction has also been accepted as a multidimensional construct (Kelcey et al. 2019). While investigating teachers' instructional practice, cognitive activation and providing student learning support have been specifically emphasized by researchers (e.g., Baumert et al. 2010; Depaepe and König 2018). In mathematics instruction, the aspect of cognitive activation refers to how cognitively challenging teachers' instructional strategies and selected tasks are for students (Kunter et al. 2013). Student support refers to the teacher's well-judged support for students' learning process, when they meet difficulties during working on the cognitively challenging tasks (Depaepe and König 2018; Kunter et al. 2013).

Many methods have been used in previous studies in order to study teachers' instructional practices, such as classroom observation conducted by external observers (mainly via video-recording), and student ratings and selfreported survey by teachers (mainly via questionnaire survey) (Depaepe and König 2018). However, either method has its own advantages and disadvantages. The self-reported way has been widely employed by researchers. With a main aim of involving a relatively large group of participants. Teachers are aware of strengths and weaknesses of their instructional practices, which should be reflected in their ratings of questionnaire items. They are able to relate the content of such items to a relatively long period of teaching time, whereas external observation usually accounts for a thin slice of teacher-student interaction in the classroom, which may limit generalization of observational data. Whereas student ratings of instructional practice are valid regarding classroom interaction visible to students, such as the prevalence of disruptive student behavior, teacher ratings are valid also concerning the evaluation of instructional concepts that are behind the visible teaching processes in the classroom (Wagner et al. 2013). However, since teacher ratings may be "biased by self-serving strategies or teaching ideals" (Kunter and Baumert, 2006, p. 231), empirical results should be interpreted with caution.

\subsection{The relationship among teacher knowledge, beliefs and instructional practice}

During the past decades, researchers explored already how teacher knowledge and teacher beliefs influence their teaching practice, especially in mathematics education. First, in terms of the relationship between MCK and teaching practice, it has been theoretically argued that teachers' MCK has a direct relationship with their instructional practices (e.g., Ernest 1989). Similarly, in the review conducted by Fennema and Franke (1992), they concluded that "when a teacher has a conceptual understanding of mathematics, it influences classroom instruction in a positive way' (p. 151). However, the empirical findings are less clear. For example,
Hill et al. (2008) reported that teachers with stronger Mathematics Knowledge for Teaching (MKT) (including common and specialized mathematics content knowledge) made fewer mathematical errors, responded more appropriately to students, and chose examples that helped students construct meaning. In contrast, Shechtman et al. (2010) found that teachers' MKT did not correlate with the three areas of instructional decision-making investigated in their study: decisions about topic coverage, choice of teaching goals, and use of technology.

Such inconsistent findings suggest on the one hand that teachers' subject matter knowledge alone does not ensure effective teaching performance (Kahan et al. 2003). On the other hand, it may imply the existence of other types of knowledge, such as pedagogical content knowledge (PCK), which might be more closely related to teachers' instructional practices. Indeed, in empirical studies PCK has been recognized as a knowledge facet needed by teachers to provide high quality instruction. For example, Baumert et al. (2010) found that, compared with teachers' MCK, teachers' MPCK was more powerful in predicting instructional quality as conceptualized by the cognitive demand of tasks used during teaching. Similarly, Speer and Wagner (2009) found that due to the lack of MPCK, even teachers having extensive teaching experience and possessing strong content knowledge still faced challenges when trying to provide analytic scaffolding to move whole-class discussions toward a lesson's mathematical goals.

Besides the fact that teachers' knowledge shapes teachers' practices, teacher beliefs, including beliefs about the nature of mathematics and its learning and teaching, have long been argued as another critical factor, which may influence teachers' instructional practice. For some researchers, compared to teacher knowledge, teacher beliefs are an even stronger influential factor. For example, as Ernest (1989) pointed out, it is possible for two teachers with similar knowledge to teach mathematics in quite different ways due to their different beliefs about the nature of mathematics and its teaching and learning.

Due to the critical role played by teacher belief in teachers' practices, many studies have investigated the relationship between the two aspects. However, the relationship between teacher beliefs and instructional practices was found to be a "subject of controversy and is acknowledged to be both subtle and complex" (Beswick 2007, p. 96). In some studies, teacher beliefs were found to be consistent with teachers' teaching practices (e.g. Wilkins 2008) and in other studies, inconsistencies between teacher beliefs and teachers' practices were reported (e.g. Raymond 1997).

However, it has been generally accepted that for the implementation of a reformed mathematics curriculum, teachers need to be equipped with corresponding beliefs about mathematics and its teaching and learning (Lloyd 
1999). If mathematics teachers' beliefs are not congruent with beliefs underpinning the reformed mathematics curriculum, then it will affect the degree of the implementation of the innovation ideas (Handal and Herrington 2003). Based on the global move towards group discussion, collaboration and inquiry ways of mathematics teaching (Paine et al. 2016), teachers' dynamic beliefs about the nature of mathematics and constructivist beliefs about mathematics teaching and learning seems to be more closely related to reform based styles of mathematics teaching.

In addition, researchers also argued that teacher knowledge and teacher beliefs interact to shape teachers' decisions and actions in classrooms (Charalambous 2015). How exactly this interaction works, however, has not been examined broadly. A few qualitative studies explored how teacher knowledge and teacher beliefs jointly influence instructional practice. For example, Zhang and Wong (2015) found that in-service mathematics teachers in China with similar professional knowledge interpreted students' mathematics learning differently due to differences in their beliefs about mathematics. Bray (2011) investigated how four American third-grade teachers' beliefs and knowledge influenced their error-handling capacity. The study found that teachers' ways of handling student errors during class discussion of mathematics were clearly linked to both teacher beliefs and teacher knowledge, with some aspects of teacher response being more strongly linked to knowledge and others being influenced more by beliefs. More recently, Charalambous (2015) also investigated how three American pre-service mathematics teachers' knowledge and beliefs interacted to influence their practices. His study found that teachers, who possessed only strong knowledge, could not ensure the creation of mathematically rich environments, and teachers with beliefs that are inconsistent with reform-based curriculum could impede teachers from performing in ways that their knowledge could otherwise have supported.

Such findings from previous qualitative studies may suggest that teacher beliefs will not only directly influence teachers' teaching practices but that they may also mediate the relationship between teacher knowledge and instructional practice (Charalambous 2015; Wilkins 2008). A few quantitative studies indeed verified the mediating role played by teacher beliefs. For example, Wilkins (2008) investigated the relationship between 481 in-service elementary teachers' MCK, their beliefs about the effectiveness of inquirybased instruction and their use of inquiry-based instruction. The study found that beliefs partially mediated the effects of content knowledge and instructional practice. Similarly, Campbell et al. (2014) investigated 266 upper-grade elementary teachers' MCK and MCPK, perceptions and students' achievement and found that teachers' beliefs regarding mathematical solutions and instruction to support incremental mastery of skills interacted with content and pedagogical content knowledge.

\subsection{A brief description of mathematics education context in Mainland China}

Due to the cultural, historical and political differences, the history of the development of mathematics education at both primary and secondary school level in Mainland China is quite different from the history of mathematics education in most Western countries. Therefore, the modern mathematics movement did not exert any influence on the development of mathematics education in Mainland China. Basic mathematics skills and traditional mathematics topics such as Euclidean geometry have kept their relevance until now (Zhang et al. 2016). Right after the establishment of The People's Republic of China in 1949, mathematics textbooks used in Mainland China were adopted directly from the former Soviet Union. Mathematics education in the former Soviet Union emphasized the rules and regulations of basic knowledge and the rigor of proof, including the training of logical reasoning (Zhang et al. 2004). Such features were not only reflected in the textbooks published in 1952 and in the subsequent revised textbooks, but also significantly influenced the ways mathematics teaching and learning were conducted in Mainland China (Xu 2013).

Against this background, even though the mathematics curriculum at primary and secondary school level in Mainland China later experienced several periods of change, a unique feature of Chinese mathematics education practice was gradually shaped, that is, 'two basics', namely, basic mathematics concepts and basic mathematics skills ( $\mathrm{Ni}$ et al. 2014; Zhang et al. 2004). A main characteristic of this culture is the emphasis on the acquisition of foundational mathematics knowledge (e.g., mathematical definitions and principles), and problem solving skills other than the development of students' creative thinking (Leung 2001, 2017). Mathematics teaching is "predominantly content orientated and exam driven. Instruction is very much teacher dominated and student involvement minimal" (Leung 2001, p. 35). In addition, students have few opportunities for group work or activities but do routine exercises individually and repeatedly in order to solve problems quickly later (Leung 2001; Ni et al. 2014).

The emphasis on accurate and abstract mathematics in mathematics classrooms and the development of students' problem solving skills under the 'two basics' mathematics education culture on the one hand equipped Chinese students with a solid foundation in mathematics, which helped them perform quite well in international comparative studies. On the other hand, limitations of this culture, such as neglecting the processes of constructing and advancing mathematics knowledge, the connections 
between different forms of knowledge, and especially the connections between mathematics and students' real lives and its application in these contexts, and students' active role in the learning of mathematics, have been recognized and criticized (Ni et al. 2014). Due to limitations of this sort, in 2001, the Chinese government started a new round of mathematics curriculum reform. Constructivism was "borrowed" from the West "as a dominant theory" (Tan 2017, p. 241), which underpins this round of mathematics curriculum reform.

Therefore, under the influence of constructivism, fundamental changes were made to the selection and inclusion of mathematics content, mathematics teaching and learning methods and assessment systems (Ni et al. 2014). Significant changes were also made to the description of mathematics itself in the reformed mathematics curriculum standards and its revised version. Instead of the excessive emphasis on the abstract and rigorous nature of mathematics, mathematics was further described as a tool, a foundation for science and technology, which is able to be applied in all the aspects of social production and daily life, and a kind of human culture as well (Ministry of Education 2001, 2011). In terms of mathematics teaching and learning methods, fundamentally, teachers were strongly encouraged to use inquiry-based mathematics instruction, which can facilitate the processes of knowledge construction and the application of knowledge. In addition, students were encouraged to use various ways of learning mathematics such as self-exploration and cooperation with their peers, rather than receiving information entirely from their teachers (Ministry of Education 2001, 2011). In other words, a significant change in mathematics instruction is encouragement for the traditional teachercentered approach to be replaced by a student-centered approach (Tan 2017).

\subsection{Research questions and hypotheses}

This study investigates the relationship between Chinese pre-service teachers' knowledge, beliefs and self-reported instructional practices, namely: MCK, MPCK, beliefs about the nature of mathematics, beliefs about mathematics teaching and learning, and instructional practices. We hypothesize the following:

- a direct effect of MCK and MPCK on instructional practice;

- a direct effect of beliefs about the nature of mathematics and beliefs about mathematics teaching and learning on teachers' instructional practice;

- a mediation role played by beliefs between MCK, MPCK and instructional practice.

\section{Methodology}

\subsection{Participants of the study}

A convenience sample of 495 pre-service mathematics teachers (369 females) participated in the study. 134 of them completed their teaching practicum in junior secondary schools and the other 359 completed their teaching practicum in senior secondary schools. Overall, all had some kind of teaching experience and all of them were trained to teach secondary school mathematics after their graduation. In China, pre-service teachers are trained in specific teacher training institutions (Normal universities or colleges) with a heavy focus on subject matter. Those 495 pre-service mathematics teachers were all in their fourth year of study and therefore close to completing their degree. They were from four Normal universities at different levels located in the western, central and coastal part of China.

Currently, in China teacher education universities generally provide 4-year bachelor's programs for pre-service teachers. Because of the influence of the national centralized curriculum system for pre-service teacher training, the curriculum in different institutions is quite similar all over China. The curriculum during pre-service mathematics teacher education includes general courses (e.g., English, general pedagogy and general psychology), mathematics subject related courses, mathematics education related courses and fieldwork or internships in schools for a semester. Around $60 \%$ of the total pre-service teacher curriculum hours are devoted to mathematics subject courses such as advanced algebra, analytical geometry, function analysis, abstract algebra, and topology (Paine et al. 2003; Li et al. 2008).

\subsection{Design of the study and instruments used}

\subsubsection{MCK and MPCK paper-pencil test}

The Chinese version of the instruments developed in TEDS-M to test pre-service mathematics teachers' MCK and MPCK used in Taiwan were directly used with slight modifications in the present study (mainly referring to the traditional writing used in Taiwan). In TEDS-M, the MCK and MPCK instruments were designed in a paper-and-pencil test style. Participants were given 60 min to complete the tests for MCK and MPCK. The lower-secondary assessment consisted of three booklets with 103 items in total: there were 76 MCK related items and 27 MPCK related items. The 103 items were distributed in the three booklets following a balanced-incomplete-block design with the aim of capturing the desired breadth and depth of teacher knowledge. 
The 76 MCK related items covered number, algebra and geometry as the main content areas of school mathematics, and, with a few items, the area of data. The 27 MPCK items covered the following two aspects: (1) curricular and planning knowledge; and (2) knowledge about how to teach mathematics. These two sets of items were given approximately equal weight. The majority of items in the MCK and MPCK instruments were complex multiplechoice items with a few open response items. The MCK and MPCK instruments were already validated in a Chinese context as they had been used in Taiwan and Singapore (in English) within the TEDS-M study, and the context of the present study was similar to this investigation. Furthermore, the released MCK and MPCK items were already validated with in-service mathematics teachers in Chongqing, a city in Mainland China (Yang et al. 2018).

\subsubsection{Mathematics-related beliefs questionnaire}

The original Chinese versions of the questionnaires designed in TEDS-M to investigate pre-service mathematics teachers' beliefs about the nature of mathematics and beliefs about learning mathematics were used in the present study. The part concerning beliefs about the nature of mathematics included 12 items in total, which were distributed into two dimensions, namely, mathematics as a process of inquiry (6 items, with items like the following sample item: "In mathematics many things can be discovered and tried out by oneself") and mathematics as a set of rules and procedures (6 items, with items like the following sample item: "Fundamental to mathematics is its logical rigor and precision"). These two dimensions represent two different major perspectives on the nature of mathematics, namely, dynamic and static perspectives.

Questions concerning beliefs about the learning of mathematics also covered two dimensions: learning mathematics through following teacher direction (labeled as the traditional view, with 6 items like the following sample item: "Pupils need to be taught exact procedures for solving mathematical problems"), and learning mathematics through active involvement (labeled as constructivist beliefs, with 6 items like the following sample item: "In addition to getting the right answer, it is important to understand why the answer is correct"). Pre-service teachers rated the beliefs statements on a five-point Likert scale ( $1=$ "strongly disagree" and $5=$ "strongly agree").

To validate the two questionnaires for the purpose of the present study, the sample of pre-service mathematics teachers was randomly distributed into two groups for exploratory factor analysis (EFA) and confirmatory factor analysis (CFA). For the beliefs about the nature of mathematics, two factors were identified in the EFA that accounted for $44.98 \%$ of the variance. One item from the scale reflecting a static view and one item from the dynamic scale with a crossfactor loading were deleted. A following CFA demonstrated a satisfactory model fit of the resulting two-factor model including 9 items $\left(\mathrm{X}^{2}=57.75, \mathrm{X}^{2} / \mathrm{df}=3.03\right.$, GFI $=.933$, TLI $=.901$, RMSEA $=.064$ ).

Concerning the beliefs about mathematics learning and teaching, two factors were also identified during EFA that accounted for $40.52 \%$ of total variance. During EFA, factor loadings of two items from the traditional beliefs scale were below 0.40 and these were deleted along with one item from the constructivist beliefs scale with cross-loading. The CFA showed that the two-factor model with 9 items had a good fit $\left(\mathrm{X}^{2}=65.36, \mathrm{X}^{2} / \mathrm{df}=2.51, \mathrm{GFI}=.941, \mathrm{TLI}=.918\right.$, RMSEA $=.055)$.

\subsubsection{Instructional practice}

The questionnaire designed in a study by Depaepe and König (2018) was adapted and validated to assess preservice mathematics teachers' self-reported instructional practices. The original items were designed to investigate general instructional practices. Therefore, all items of the two dimensions, cognitive activation and providing learning support to students, were especially modified according to the mathematics teaching context concerning the mathematics education reality in China and inquiry-oriented mathematics teaching as emphasized in the recent mathematics curriculum standard in China. Sub-dimensions included in the scale were as follows:

(1) for cognitive activation, which includes two sub-dimensions: (1) the use of cognitively demanding tasks (4 items). One item, "I gave students mathematical challenging tasks" was added to the sub-dimension, which originally had three items. In addition, the original item "I asked the students questions that they had really to think about" was modified as "I asked students mathematics questions they had to really think about"; and (2) stimulating students' cognitive independence (5 items). Two items, like "In mathematics teaching, I encouraged students to find solutions from different perspectives" were added to the original three items in this sub-dimension;

(2) student support, which includes two sub-dimensions: (1) encouraging students (4 items); all the four original items, such as "I supported students additionally when they needed help", were directly used since all of them met the mathematics education situation in China; and (2) dealing with student heterogeneity (4 items); mathematics education related information was added to the original four items in the sub-dimension. Items were rated on a four-point Likert scale ( $1=$ "strongly disagree" and $4=$ "strongly agree"). 
The content of the 17 items was validated by two experienced secondary school mathematics teachers and modifications were made according to their comments. In addition, EFA and CFA were performed for construct validation of the modified questionnaire. During EFA, the four sub-dimensions were identified that accounted for $59.93 \%$ of the total variance. The sub-dimension, encouraging students and dealing with student heterogeneity, had one cross-factor loading item and this item was deleted. The CFA confirmed that the two-factor model with the 16 remaining items had a good fit with the latent constructs $\left(\mathrm{X}^{2}=309.57, \mathrm{X}^{2} / \mathrm{df}=2.69, \mathrm{GFI}=.938, \mathrm{TLI}=.927\right.$, RMSEA $=.058)$.

For data collection, participants from each of the four universities were distributed into two lecture rooms and completed the knowledge test and beliefs survey individually at the same time. All the participants were given 60 min for the knowledge test and 20 min for the beliefs survey and the questionnaire on self-reported instruction, with a 10-min break between them.

\subsection{Data analysis}

Besides the validation analysis for the instruments as mentioned above, the data analysis was comprised of the following steps. First, the open response items were coded following the TEDS-M coding rubrics. For each of the booklets, $20 \%$ of the open response items were coded by two independent trained raters. Cohen's Kappa indicated high agreement $\left(\mathrm{k}>0.89\right.$ and $\left.\mathrm{K}_{\text {average }}=0.92\right)$. With respect to the multiple-choice and complex multiple-choice items, items with no response or an incorrect response were coded as 0 , and each correct answer was coded as 1. After the completion of coding, item response theory (IRT) scaling methods were used to estimate scale scores for MCK and MPCK. One-dimensional Rasch model (1 parameter model) was used to analyze test data, and the internal consistency of the overall MCK and MPCK was examined using Expected a Posteriori estimation (EAP). Reliability coefficients of MCK and MPCK were 0.82 and 0.79 respectively. The second step of the data analysis was descriptive analysis. Means and standard deviations for all scales were computed.

The third step of data analysis was to examine the relationship between teacher knowledge, beliefs and instructional practice. Manifest correlations were estimated between pre-service mathematics teachers' MCK, MPCK, their mathematics-related beliefs and their self-reported instructional practices. Subsequently, path analysis was conducted to examine the interactive function of knowledge and belief to instructional practice. Mplus was used for the path analyses.

\section{Findings}

\subsection{Descriptive results}

As shown in Table 1, in terms of the beliefs about the nature of mathematics, relatively speaking, the item mean score of dynamic beliefs is greater than the item mean score of static beliefs, which illustrates that pre-service mathematics teachers' dynamic beliefs about mathematics are stronger than their static beliefs. However, the mean score of the static beliefs is also greater than 3 , which indicates that the participants in this study tend to hold mixed beliefs about the nature of mathematics.

Regarding the beliefs about mathematics teaching and learning, the item mean score of traditional teaching is quite close to 2 and the item mean score of constructivist teaching is greater than 4 . Such results suggest that our sample of Chinese pre-service mathematics teachers reject traditional beliefs about mathematics teaching and learning; instead they hold constructivist beliefs about mathematics teaching and learning.

With respect to pre-service mathematics teachers' selfreported instructional practice, mean scores of three of the aspects, namely the use of cognitively demanding tasks, stimulating students' cognitive independence, and encouraging students, are quite close to 3.5 (maximum is 4), and the mean score of the final aspect is 3.30, which suggest that the participants evaluated their teaching as inquiry-oriented.

\subsection{Correlational analysis results}

In terms of the correlation between two tested knowledge variables (MCK and MPCK) and beliefs and self-reported practices, as shown in Table 2, both MCK and MPCK were found to be positively and significantly correlated with

Table 1 Overview of the descriptive results of pre-service teachers' knowledge, beliefs and instructional practice and internal consistency reliability of the instruments

\begin{tabular}{lcccl}
\hline & Min. & Max. & Mean \pm SD & $\alpha$ reliability \\
\hline MCK & -4.22 & 1.65 & $0.03 \pm 0.70$ & \\
MPCK & -1.71 & 1.41 & $0.02 \pm 0.75$ & \\
Static belief (SB) & 1 & 5 & $3.38 \pm 0.57$ & 0.632 \\
Dynamic belief (DB) & 3 & 5 & $4.30 \pm 0.45$ & 0.692 \\
Traditional teaching (TT) & 1 & 4 & $2.22 \pm 0.47$ & 0.684 \\
Constructivist teaching & 2 & 5 & $4.35 \pm 0.47$ & 0.673 \\
$\quad$ (CT) & & & & \\
IP_CA_1 & 2 & 4 & $3.46 \pm 0.48$ & 0.779 \\
IP_CA_2 & 2 & 4 & $3.57 \pm 0.45$ & 0.737 \\
IP_SS_1 & 2 & 4 & $3.56 \pm 0.48$ & 0.719 \\
IP_SS_2 & 2 & 4 & $3.30 \pm 0.58$ & 0.846
\end{tabular}


Table 2 Matrix of the bivariate manifest correlations

\begin{tabular}{|c|c|c|c|c|c|c|c|c|c|c|}
\hline & MCK & MPCK & SB & DB & TT & CT & CA_1 & CA_2 & SS_1 & SS_2 \\
\hline MCK & & $0.38 * * *$ & -0.08 & $0.14 * *$ & $-0.18 * * *$ & $0.16^{* * *}$ & 0.09 & 0.02 & 0.02 & 0.08 \\
\hline MPCK & & & -0.07 & $0.14 * *$ & $-0.16^{* * *}$ & $0.19 * * *$ & $0.10 *$ & 0.06 & 0.04 & 0.01 \\
\hline SB & & & & $0.21 * * *$ & $0.36^{* * *}$ & 0.06 & 0.11 & 0.03 & 0.06 & $0.14 * *$ \\
\hline DB & & & & & $-0.13 * *$ & $0.53 * * *$ & $0.34 * * *$ & $0.33 * * *$ & $0.27 * * *$ & $0.25^{* * *}$ \\
\hline $\mathrm{TT}$ & & & & & & $-0.16^{* * *}$ & -0.06 & -0.07 & -0.02 & -0.03 \\
\hline $\mathrm{CT}$ & & & & & & & $0.28 * * *$ & $0.33^{* * *}$ & $0.26^{* * *}$ & $0.25^{* * *}$ \\
\hline CA_1 & & & & & & & & $0.35 * * *$ & $0.25 * * *$ & $0.28 * * *$ \\
\hline CA_2 & & & & & & & & & $0.36 * * *$ & $0.28 * * *$ \\
\hline SS_1 & & & & & & & & & & $0.21 * * *$ \\
\hline SS_2 & & & & & & & & & & \\
\hline
\end{tabular}

${ }^{*} p<0.05 ; * * p<0.01 ; * * * p<0.001$

$M C K$ mathematics content knowledge, $M P C K$ mathematics pedagogical content knowledge, $S B$ static beliefs, $D B$ dynamic beliefs, $T T$ traditional beliefs, $C T$ constructivist beliefs, $C A \_1$ use of cognitively demanding tasks, $C A \_2$ stimulating students' cognitive independence, $S S \_1$ encouraging students, $S S \_2$ dealing with student heterogeneity

pre-service teachers' dynamic beliefs about the nature of mathematics and constructivist beliefs about mathematics teaching and learning. Weak negative associations were observed between the two knowledge variables, MCK and MPCK, and traditional teaching and learning beliefs, while no systematic relation existed comparing these to static beliefs about the nature of mathematics. However, except for one weak positive association between MPCK and one subaspect of self-reported instructional practice, the use of cognitively demanding tasks, all the associations between the two knowledge variables and other sub-aspects of instructional practice were found to be positive but insignificant.

As to the correlation between beliefs about the nature of mathematics and the other constructs, moderate and positive significant associations were identified between static beliefs about the nature of mathematics and traditional beliefs about mathematics teaching and learning, as well as between dynamic beliefs about the nature of mathematics and constructivist beliefs about mathematics teaching and learning. No associations were identified between static beliefs about the nature of mathematics and the four sub-aspects of selfreported instructional practice. However, relatively stronger significant and positive associations were identified between dynamic beliefs about the nature of mathematics and the four sub-aspects of instructional practice.

Similar patterns were also identified between pre-service mathematics teachers' beliefs about mathematics teaching and learning and self-reported instructional practices. As shown in Table 2, negative but only weak associations ( $\mathrm{r}$ is between -0.07 and -0.02 ) were observed between traditional beliefs about mathematics teaching and learning and the four sub-aspects of self-reported instructional practice. However, relatively stronger positively significant associations ( $\mathrm{r}$ is between 0.25 and 0.33 ) were observed between constructivist beliefs about mathematics teaching and learning and the four sub-dimensions of instructional practice.

\subsection{Path analysis results}

Basing on the results of association analysis, a path analysis was performed to examine the relationship between pre-service mathematics teachers' MCK, MPCK, dynamic beliefs about mathematics, constructivist beliefs about mathematics teaching and learning, and instructional practice. The final path model fits the data well, $\mathrm{X}^{2}=339.11, \mathrm{X}^{2} / \mathrm{df}=2.35$, $\mathrm{GFI}=.928, \mathrm{TLI}=.925, \mathrm{CFI}=.936$, RMSEA $=.052$. The path coefficients for the final model are presented in Fig. 1.

Firstly, as shown in Fig. 1, both dynamic beliefs about the nature of mathematics and constructivist beliefs about mathematics teaching and learning positively and significantly predicted pre-service mathematics teachers' self-reported instructional practices ( $\beta=0.31$ and 0.22 respectively). Secondly, it was found that MPCK was positively associated with pre-service mathematics teachers' dynamic beliefs about the nature of mathematics $(\beta=0.10)$ and constructivist

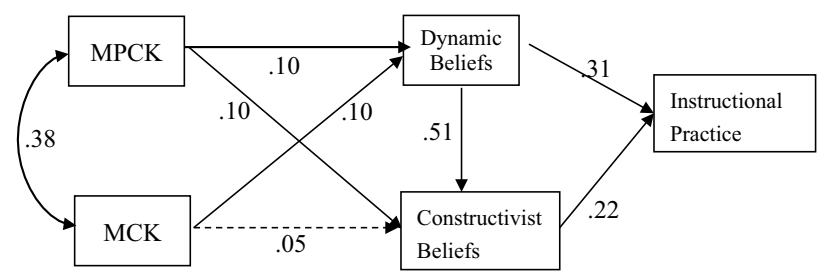

Fig. 1 Path analysis results for the relationship among MCK, MPCK, dynamic beliefs about the nature of mathematics, constructivist beliefs about mathematics teaching and learning, and instructional practice. Note: the dotted line represent non-significant path coefficients 
beliefs about mathematics teaching and learning $(\beta=0.10)$, however, MCK was positively associated only with dynamic beliefs about the nature of mathematics $(\beta=0.10)$. Thirdly, the results showed that MPCK, through the mediation of both dynamic beliefs about mathematics and constructivist beliefs about mathematics teaching and learning, have indirect and positive effect on instructional practice (total indirect effect $\beta=0.06$ ). MCK was found to predict instructional practice only indirectly through the mediation of dynamic beliefs about the nature of mathematics (total indirect effect $\beta=0.05$ ), not the constructivist beliefs about mathematics teaching and learning.

\section{Discussion}

Based on the adaptation of the instruments developed in the TEDS-M study and related studies, in the present study we investigated 495 pre-service mathematics teachers' knowledge, mathematics beliefs, self-reported instructional practice and the relationship between the three variables. As reported above, in terms of pre-service teachers' beliefs about the nature of mathematics, the surveyed teachers were found to agree on both the static and dynamic aspect of mathematics. This result suggests that the pre-service teachers tend to hold mixed beliefs about the nature of mathematics as was reported in previous studies for pre-service teachers at the end of teacher education (e.g., Felbrich et al. 2012; Tang and Hsieh 2014). For teachers' beliefs about mathematics teaching and learning, the study reports a strong tendency to hold a constructivist rather than a traditional view. Overall, it seems that pre-service mathematics teachers' dynamic beliefs about the nature of mathematics and constructivist beliefs about mathematics teaching and learning display a certain degree of psychological strength, and therefore, these two aspects may be considered as "core beliefs" (Cross 2009, p. 327). Moreover, the surveyed Chinese pre-service mathematics teachers were found to tend to believe that their teaching is inquiry-oriented.

Chinese pre-service mathematics teachers' constructivist views of mathematics teaching and learning and selfreported inquiry-oriented instructional practices, together with their views of the nature of mathematics, are all not consistent with findings identified in previous studies related to Chinese teachers. It was found in previous comparative studies that teachers from Eastern countries and regions (e.g., Mainland China and Hong Kong) tend to hold a more rigid view of mathematics, or they mainly focus on the internal and logical structure of mathematics (Bryan et al. 2007; Leung 1995). For their pedagogical beliefs, in-service mathematics teachers from Mainland China and Hong Kong were also found to place more emphasis on abstract reasoning and verbal engagement over physical engagement, and with fewer in-class group activities (Bryan et al., 2007; Cai and Wang 2010).

Such inconsistencies may imply, first, that pre-service mathematics teachers are already equipped with ideas emphasized in the reformed mathematics curriculum in China as described above. Since the latest national reformed mathematics curriculum was started in 2000 , a dynamic view of mathematics and a learner-centered view about mathematics learning and teaching have been promulgated in China since then. Therefore, pre-service mathematics teachers have not only experienced the reformed mathematics curriculum when they were students in schools. In addition, these reformed views have been integrated into preservice teacher training curricula and emphasized during the pre-service training period ( $\mathrm{Ni}$ et al. 2014). Therefore, such schooling and pre-service training experience apparently allowed them to gradually accept the reformed ideas in terms of the nature of mathematics and the ways mathematics teaching and learning should take place.

In addition, the correlation analysis and path analysis results reported above first suggest that both of the two knowledge variables, MCK and MPCK, did not significantly correlate with pre-service mathematics teachers' selfreported instructional practices. The insignificant association between MCK and instructional practice is consistent with findings identified in previous studies (e.g., Baumert et al. 2010). For example, Wilkins (2008) found that the increase of teachers' content knowledge did not predict teachers' increased use of inquiry-based instructional practice, in contrast, content knowledge was found to have a negative effect on teachers' use of inquiry-based instructional practice. Similar findings were also reported in studies by Hill et al. (2008) and Shechtman et al. (2010).

However, it is quite interesting that pre-service mathematics teachers' MPCK did not significantly correlate with their self-reported inquiry-oriented instructional practices, as MPCK has been widely accepted in literature as the predominant knowledge that is needed for teachers' effective teaching practice. As mentioned above, in empirical studies conducted in Western contexts, for example, in Germany, MPCK was found to be even more powerful in predicting teachers' instructional quality. However, considering the policy and practice of initial teacher education in China and especially curricular requirements for pre-service mathematics teachers, it may not be that difficult to understand the insignificant association. In China, during the pre-service training period, more than $60 \%$ of the courses are subjectrelated theoretical courses, and only a limited number of courses are related to pedagogy, including mathematics education methods, and teaching skills practice (Paine et al. 2003). Such a tradition may provide pre-service mathematics teachers with quite limited opportunities to improve their MPCK and relate it to practical situations of instructional 
quality. Therefore, during their teaching practicum period, with the help of their mentors and their own observations in schools, most of them may acquire inquiry-based teaching skills, but this acquisition will not necessarily guarantee a significant association between MPCK and their selfreported instructional practices.

A second clear pattern, which could be identified from correlation analysis and path analysis is that pre-service mathematics teachers' dynamic beliefs about the nature of mathematics and constructivist beliefs about mathematics teaching and learning are relatively strongly and significantly associated with their self-reported instructional practices. Such findings are consistent with theoretical assumptions related to the effective implementation of the inquiry-based mathematics curriculum. It has been widely accepted for decades in the literature that "the quality of teaching and learning will improve if teachers hold beliefs that are supportive of constructivist-based, student-centered practices" (Francis et al. 2014, p. 340). Similar empirical findings indeed have been identified in previous studies (e.g., Handal and Herrington 2003; Lloyd 1999). Such findings further imply that pre-service mathematics related beliefs about dynamic aspects of mathematics and constructivist aspects of mathematics teaching and learning indeed are aligned with their teaching practices.

Moreover, relatively speaking, pre-service mathematics teachers' dynamic beliefs about mathematics and constructivist pedagogical beliefs showed a stronger association with, or have stronger power in, predicting their selfreported inquiry-oriented instructional practices than their knowledge. This finding is also consistent with results from previous studies in terms of the relationship between teacher knowledge and their practices and the relationship between teacher beliefs and their practices (e.g., Cooney 2001; Ernest 1989). Similarly, Wilkins (2008) also found that teachers' beliefs had the strongest overall effect on teachers' use of inquiry-based instructional practices. However, this finding is not consistent with findings identified in more recent studies. For example, Lui and Bonner (2016) identified a significant positive relationship between teachers' conceptual mathematics knowledge and instructional plans, but no relationship between teachers' constructivist beliefs about mathematics teaching and learning. Such mixed consistency or inconsistency suggest that more studies are needed in this field for a fuller understanding of the complex relationships among these three aspects.

Furthermore, the present study indicated that pre-service teachers' dynamic beliefs about the nature of mathematics and constructivist beliefs about mathematics teaching and learning acted as mediators between pre-service mathematics teachers' MCK, MPCK and instructional practice respectively. Such findings on the one hand support the results of previous studies, and the results of the present study are also in agreement that teachers' knowledge will indirectly influence teachers' instructional practices through the mediation of teachers' beliefs (Ernest 1989; Wilkins 2008). Beliefs may be regarded as a 'filter' through which pre-service teachers evaluate their teaching behavior in the classroom (Ernest 1989; Philipp 2007), which in turn influences their self-reported instructional practices. That means that teacher knowledge and teacher beliefs will to a certain degree interact together to shape teachers' teaching practices (Charalambous, 2015). However, on the other hand, these findings suggest that only certain types of beliefs, or core beliefs with certain psychological strength, may play the mediator role, especially the beliefs that tend to be aligned with teachers' instructional practices. Of course, as pointed out in previous studies (e.g., Charalambous 2015; Wilkins 2008), more studies, especially quantitative studies, are needed before a concrete conclusion can be developed.

\section{Conclusion and implication}

As reported above, findings of our study show that both of the two knowledge variables, MCK and MPCK, did not correlate with teachers' self-reported instructional practices. Pre-service mathematics teachers' beliefs showed a stronger association with their self-reported inquiry-orientated instructional practices. However, only pre-service teachers' core beliefs, namely dynamic beliefs about the nature of mathematics and constructivist beliefs about mathematics teaching and learning, were found to act as main mediator between pre-service mathematics teachers' MCK, MPCK and instructional practice respectively.

Overall, the study also has several limitations, which should also be discussed. Firstly, concerning the data collection methods, one large limitation is the usage of a selfreport questionnaire survey to collect data on pre-service teachers' instructional practices. Therefore, it might be possible that in reality, these teachers taught in a different way. In addition, a paper-and-pencil test was used to assess preservice mathematics teachers' MCK and MPCK, however, teacher beliefs and instructional practice were measured through self-reports. The differences in data collections methods may also have led to the relatively strong association between teacher beliefs and instructional practice, and the insignificant association between teacher knowledge and instructional practice. Therefore, as suggested in previous similar studies (e.g., Depaepe and König 2018), future studies should consider combining other data sampling methods with the questionnaire survey, for example, classroom observation or video recording methods, to analyze teachers' instructional practice, in order to avoid measurement errors.

Secondly, the study tested and required the pre-service teachers to answer the questionnaires only once. It might be 
possible that after the pre-service mathematics teachers actually worked in schools, especially after a couple of years, not only their knowledge, their beliefs and even the ways they used to teach mathematics would be changed significantly. Therefore, a longitudinal design of a study might be helpful not only to fully understand the relationships between the three variables, but also the change of relationships of the three variables when teachers are in different professional development stages.

Based on the involvement of a relatively large number of pre-service mathematics teachers in China, the central goal of the present study was to explore the relationship between teacher knowledge, teacher beliefs, and their self-reported inquiry-oriented instructional practices. So far, this study is one of the very few quantitative studies in the field of mathematics teacher education to explore the interactive effect of teacher knowledge and teacher beliefs on teachers' instructional practice in a non-Western context. Therefore, the findings identified in the present study can provide empirical evidence for the understanding of the relation between the three factors.

Acknowledgments Open Access funding provided by Projekt DEAL.

Funding Funding was provided by Fundamental Research Funds for the Central Universities (Grant No. XDJK2016B013).

Open Access This article is licensed under a Creative Commons Attribution 4.0 International License, which permits use, sharing, adaptation, distribution and reproduction in any medium or format, as long as you give appropriate credit to the original author(s) and the source, provide a link to the Creative Commons licence, and indicate if changes were made. The images or other third party material in this article are included in the article's Creative Commons licence, unless indicated otherwise in a credit line to the material. If material is not included in the article's Creative Commons licence and your intended use is not permitted by statutory regulation or exceeds the permitted use, you will need to obtain permission directly from the copyright holder. To view a copy of this licence, visit http://creativecommons.org/licenses/by/4.0/.

\section{References}

Adler, J., Ball, D., Krainer, K., Lin, F. L., \& Novotna, J. (2005). Reflections on an emerging field: Researching mathematics teacher education. Educational Studies in Mathematics, 60(3), 359-381.

Artzt, A. F., \& Armour-Thomas, E. (1999). A cognitive model for examining teachers' instructional practice in mathematics: A guide for facilitating teacher reflection. Educational Studies in Mathematics, 40(3), 211-235.

Ball, D. L., Thames, M. H., \& Phelps, G. (2008). Content knowledge for teaching: What makes it special? Journal of Teacher Education, 59, 389-407.

Baumert, J., Kunter, M., Blum, W., Brunner, M., Voss, T., Jordan, A., et al. (2010). Teachers' mathematical knowledge, cognitive activation in the classroom, and student progress. American Educational Research Journal, 47(1), 133-180.
Beswick, K. (2007). Teachers' beliefs that matter in secondary mathematics classrooms. Educational Studies in Mathematics, 65, 95-120.

Blömeke, S., \& Delaney, S. (2012). Assessment of teacher knowledge across countries: A review of the state of research. ZDM Mathematics Education, 44(3), 223-247.

Blömeke, S., \& Kaiser, G. (2014). Theoretical framework, study design and main results of TEDS-M. In S. Blömeke, F. J. Hsieh, G. Kaiser, \& W. H. Schmidt (Eds.), International perspectives on teacher knowledge, beliefs and opportunities to learn (pp. 19-48). Dordrecht: Springer.

Bray, W. S. (2011). A collective case study of the influence of teachers' beliefs and knowledge on error-handling practices during class discussion of mathematics. Journal for Research in Mathematics Education, 42(1), 2-38.

Bryan, C. A., Wang, T., Perry, B., Wong, N. Y., \& Cai, J. (2007). Comparison and contrast: similarities and differences of teachers' views of effective mathematics teaching and learning from four regions. ZDM Mathematics Education, 39(4), 329-340.

Cai, J., \& Howson, G. (2013). Toward an international mathematics curriculum. In M. A. K. Clements, A. J. Bishop, C. Keitel, J. Kilpatrick, \& F. K. S. Leung (Eds.), Third international handbook of mathematics education (pp. 949-974). New York: Springer.

Cai, J., \& Wang, T. (2010). Conceptions of effective mathematics teaching within a cultural context: Perspectives of teachers from China and the United States. Journal of Mathematics Teacher Education, 13(3), 265-287.

Campbell, P. F., Rust, A. H., Nishio, M., DePiper, J. N., Smith, T. M., Frank, T. J., et al. (2014). The relationship between teachers' mathematical content and pedagogical knowledge, teachers' perceptions, and student achievement. Journal for Research in Mathematics Education, 45(4), 419-459.

Chan, K. W., \& Elliott, R. G. (2004). Relational analysis of personal epistemology and conceptions about teaching and learning. Teaching and Teacher Education, 20(8), 817-831.

Charalambous, C. Y. (2015). Working at the intersection of teacher knowledge, teacher beliefs, and teaching practice: A multiplecase study. Journal of Mathematics Teacher Education, 18(5), $427-445$.

Cooney, T. J. (2001). Considering the paradoxes, perils, and purposes of conceptualizing teacher development. In F.-L. Lin (Ed.), Making sense of mathematics teacher education (pp. 9-31). Dordrecht: Kluwer Academic Publishers.

Cross, D. I. (2009). Alignment, cohesion, and change: Examining mathematics teachers' belief structures and their influence on instructional practices. Journal of Mathematics Teacher Education, 12(5), 325-346.

Depaepe, F., \& König, J. (2018). General pedagogical knowledge, self-efficacy and instructional practice: Disentangling their relationship in pre-service teacher education. Teaching and Teacher Education, 69, 177-190.

Döhrmann, M., Kaiser, G., \& Blömeke, S. (2012). The conceptualization of mathematics competencies in the international teacher education study TEDS-M. ZDM Mathematics Education, 3(44), $325-340$.

Ernest, P. (1989). The knowledge, beliefs and attitudes of the mathematics teacher: A model. Journal of Education for Teaching, 15(1), 13-33.

Felbrich, A., Kaiser, G., \& Schmotz, C. (2012). The cultural dimension of beliefs: An investigation of future primary teachers' epistemological beliefs concerning the nature of mathematics in 15 countries. ZDM Mathematics Education, 44(3), 355-366.

Fennema, E., \& Franke, M. L. (1992). Teachers' knowledge and its impact. In D. A. Grouws (Ed.), Handbook of research on 
mathematics teaching and learning (pp. 147-164). New York: Macmillan.

Francis, D. C., Rapacki, L., \& Eker, A. (2014). The individual, the context, and practice: A review of the research on teachers' beliefs related to mathematics. International handbook of research on teachers' beliefs. In H. Fives \& M. G. Gill (Eds.), International handbook of research on teachers' beliefs (pp. 336-352). New York, NY: Routledge.

Grigutsch, S., Raatz, U., \& Törner, G. (1998). Einstellungen gegenüber Mathematik bei Mathematiklehrern. Journal für MathematikDidaktik, 19, 3-45.

Handal, B., \& Herrington, A. (2003). Mathematics teachers' beliefs and curriculum reform. Mathematics Education Research Journal, 15(1), 59-69.

Hill, H. C., Blunk, M. L., Charalambous, C. Y., Lewis, J. M., Phelps, G. C., Sleep, L., et al. (2008). Mathematical knowledge for teaching and the mathematical quality of instruction: An exploratory study. Cognition and Instruction, 26(4), 430-511.

Hogan, D., Chan, M., Rahim, R., Kwek, D., Maung Aye, K., Loo, S. C., et al. (2013). Assessment and the logic of instructional practice in Secondary 3 English and mathematics classrooms in Singapore. Review of Education, 1(1), 57-106.

Kahan, J. A., Cooper, D. A., \& Bethea, K. A. (2003). The role of mathematics teachers' content knowledge in their teaching: A framework for research applied to a study of student teachers. Journal of Mathematics Teacher Education, 6(3), 223-252.

Kelcey, B., Hill, H. C., \& Chin, M. J. (2019). Teacher mathematical knowledge, instructional quality, and student outcomes: A multilevel quantile mediation analysis. School Effectiveness and School Improvement, 30(4), 1-34.

Kleickmann, T., Richter, D., Kunter, M., Elsner, J., Besser, M., Krauss, S., et al. (2013). Teachers' content knowledge and pedagogical content knowledge: The role of structural differences in teacher education. Journal of Teacher Education, 64(1), 90-106.

König, J., Blömeke, S., Klein, P., Suhl, U., Busse, A., \& Kaiser, G. (2014). Is teachers' general pedagogical knowledge a premise for noticing and interpreting classroom situations? A videobased assessment approach. Teaching and Teacher Education, $38,76-88$.

Krauss, S., Brunner, M., Kunter, M., Baumert, J., Blum, W., Neubrand, M., et al. (2008). Pedagogical content knowledge and content knowledge of secondary mathematics teachers. Journal of Educational Psychology, 100(3), 716-725.

Kunter, M., \& Baumert, J. (2006). Who is the expert? Construct and criteria validity of student and teacher ratings of instruction. Learning Environments Research, 9(3), 231-251.

Kunter, M., Klusmann, U., Baumert, J., Richter, D., Voss, T., \& Hachfeld, A. (2013). Professional competence of teachers: Effects on instructional quality and student development. Journal of Educational Psychology, 105(3), 805-820.

Leder, G. (2019). Mathematics-related beliefs and affect. In M. Hannula, G. Leder, F. Morselli, M. Vollstedt, \& Q. Zhang (Eds.), Affect and mathematics education, fresh perspectives on motivation, engagement, and identity (pp. 15-35). Cham: Springer.

Leung, F. K. (1995). The mathematics classroom in Beijing, Hong Kong and London. Educational Studies in Mathematics, 29(4), 297-325.

Leung, F. K. (2001). In search of an East Asian identity in mathematics education. Educational Studies in Mathematics, 47(1), $35-51$.

Leung, F. K. S. (2017). Making sense of mathematics achievement in East Asia: Does culture really matter? In G. Kaiser (Ed.), Proceedings of the 13th international congress on mathematical education (pp. 201-218). Cham: Springer.
Lloyd, G. M. (1999). Two teachers' conceptions of a reform-oriented curriculum: Implications for mathematics teacher development. Journal of Mathematics Teacher Education, 2(3), 227-252.

Lui, A. M., \& Bonner, S. M. (2016). Preservice and inservice teachers' knowledge, beliefs, and instructional planning in primary school mathematics. Teaching and Teacher Education, 56, 1-13.

Ministry of Education. (2001). Curriculum standards for school mathematics of nine-year compulsory education (trial version). Beijing, China: Beijing Normal University Press.

Ministry of Education. (2011). Curriculum standards for school mathematics of nine-year compulsory education (2011 version). Beijing, China: Beijing Normal University Press.

Ni, Y., Zhou, D., Li, X., \& Li, Q. (2014). Relations of instructional tasks to teacher-student discourse in mathematics classrooms of Chinese primary schools. Cognition and Instruction, 32(1), 2-43.

OECD. (2019). PISA 2018 results (volume I): What students know and can do (Summary). Paris: OECD Publishing. https://doi. org/10.1787/a9b5930a-en.

Paine, L., Blömeke, S., \& Aydarova, O. (2016). Teachers and teaching in the context of globalization. In D. H. Gitomer \& C. A. Bell (Eds.), Handbook of research on teaching (5th ed., pp. 717-786). Washington, DC: AERA.

Paine, L. W., Fang, Y., \& Wilson, S. (2003). Entering a culture of teaching. In E. Britton, L. Paine, D. Pimm, \& S. Raizen (Eds.), Comprehensive teacher induction: Systems for early career learning (pp. 20-82). Dordrecht: Kluwer.

Petrou, M., \& Goulding, M. (2011). Conceptualizing teachers' mathematical knowledge in teaching. In T. Rowland \& K. Ruthven (Eds.), Mathematical knowledge in teaching (pp. 9-25). London: Springer.

Philipp, R. (2007). Mathematics teachers' beliefs and affect. In F. K. Lester (Ed.), Second handbook of research on mathematics teaching and learning (pp. 257-315). Charlotte, NC: Information Age Publishing.

Raymond, A. M. (1997). Inconsistency between a beginning elementary school teacher's mathematics beliefs and teaching practice. Journal for Research in Mathematics Education, 28(5), 550-576.

Schleppenbach, M., Flevares, L. M., Sims, L. M., \& Perry, M. (2007). Teachers' responses to student mistakes in Chinese and US mathematics classrooms. The Elementary School Journal, 108(2), 131-147.

Schoenfeld, A. H. (1998). Toward a theory of teaching-in-context. Issues in Education, 4(1), 1-94.

Shechtman, N., Roschelle, J., Haertel, G., \& Knudsen, J. (2010). Investigating links from teacher knowledge, to classroom practice, to student learning in the instructional system of the middleschool mathematics classroom. Cognition and Instruction, 28(3), 317-359.

Shulman, L. S. (1986). Those who understand: A conception of teacher knowledge. American Educator, 10(1), 43-44.

Shulman, L. (1987). Knowledge and teaching: Foundations of the new reform. Harvard Educational Review, 57, 1-22.

Speer, N. M. (2005). Issues of methods and theory in the study of mathematics teachers' professed and attributed beliefs. Educational Studies in Mathematics, 58, 361-391.

Speer, N. M., \& Wagner, J. F. (2009). Knowledge needed by a teacher to provide analytic scaffolding during undergraduate mathematics classroom discussions. Journal for Research in Mathematics Education, 40(5), 530-562.

Stigler, J., \& Hiebert, J. (1999). The teaching gap: Best ideas from the world's teachers for improving education in the classroom. New York: Free Press.

Tan, C. (2017). Constructivism and pedagogical reform in China: Issues and challenges. Globalisation, Societies and Education, $15(2), 238-247$. 
Tang, S. J., \& Hsieh, F. J. (2014). The cultural notion of teacher education: Future lower secondary teachers' beliefs on the nature of mathematics, the learning of mathematics and mathematics achievement. In S. Blömeke, F. J. Hsieh, G. Kaiser, \& W. Schmidt (Eds.), International perspectives on teacher knowledge, beliefs and opportunities to learn (pp. 231-253). New York: Springer.

Tatto, M. T., Schwille, J., Senk, S. L., Ingvarson, L., Peck, R., \& Rowley, G. (2008). Teacher Education and Development Study in Mathematics (TEDS-M): Policy, practice, and readiness to teach primary and secondary mathematics. East Lansing: Teacher Education and Development International Study Center, College of Education, Michigan State University.

Thompson, A. G. (1992). Teachers' beliefs and conceptions: A synthesis of the research. In D. A. Grouws (Ed.), Handbook of research on mathematics teaching and learning (pp. 127-146). New York: MacMillan.

Wagner, W., Göllner, R., Helmke, A., Trautwein, U., \& Lüdtke, O. (2013). Construct validity of student perceptions of instructional quality is high, but not perfect: Dimensionality and generalizability of domain-independent assessments. Learning and Instruction, $28,1-11$.

Wilkins, J. L. (2008). The relationship among elementary teachers' content knowledge, attitudes, beliefs, and practices. Journal of Mathematics Teacher Education, 11(2), 139-164.

$\mathrm{Xu}$, B. (2013). The development of school mathematics textbooks in China since 1950. ZDM Mathematics Education, 45(5), 725-736.

Xu, L., \& Clarke, D. (2013). Meta-rules of discursive practice in mathematics classrooms from Seoul, Shanghai and Tokyo. ZDM Mathematics Education, 45(1), 61-72.
Xu, L., \& Clarke, D. (2019). Speaking or not speaking as a cultural practice: Analysis of mathematics classroom discourse in Shanghai, Seoul, and Melbourne. Educational Studies in Mathematics, 102(1), 127-146.

Yang, X., Kaiser, G., König, J., \& Blömeke, S. (2018). Measuring Chinese teacher professional competence: adapting and validating a German framework in China. Journal of Curriculum Studies, 50(5), 638-653.

Zhang, Q., Barkatsas, T., Law, H. Y., Leu, Y. C., Seah, W. T., \& Wong, N. Y. (2016). What primary students in the Chinese Mainland, Hong Kong and Taiwan value in mathematics learning: A comparative analysis. International Journal of Science and Mathematics Education, 14(5), 907-924.

Zhang, D., Li, S., \& Tang, R. (2004). The "Two Basics": Mathematics teaching and learning in mainland in China. In L. Fan, W. N.-Y. Wong, J. Cai, \& S. Li (Eds.), How Chinese learn mathematics: Perspectives from insiders (pp. 189-207). Singapore: World Scientific.

Zhang, Q. P., \& Wong, N. Y. (2015). Beliefs, knowledge and teaching: A series of studies among Chinese mathematics teachers. In L. Fan, N. Y. Wong, J. Cai, \& S. Li (Eds.), How Chinese teach mathematics: Perspectives from insiders (pp. 457-492). Singapore: World Scientific.

Publisher's Note Springer Nature remains neutral with regard to jurisdictional claims in published maps and institutional affiliations. 